\title{
Siblings, multiple births, and the incidence of allergic disease: a birth cohort study using the West Midlands general practice research database
}

\author{
T M McKeever, S A Lewis, C Smith, J Collins, H Heatlie, M Frischer, R Hubbard
}

\begin{abstract}
Background-The presence of older siblings reduces the risk of developing hay fever, eczema and atopy, but findings for asthma have been inconsistent. Whether twins have a reduced risk of allergic disease is also unclear. We have investigated these questions in a birth cohort analysis of the West Midlands General Practice Research Database (GPRD). Methods-Our birth cohort included 29238 children. The incidence of allergic disease was examined according to the number of siblings, multiple births, and parental allergic disease and smoking habit using Cox regression.
\end{abstract}

Results-There was a dose related decrease in the incidence of eczema and hay fever with increasing number of older siblings (hazard ratio for children with three or more older siblings compared with none $0.70(95 \%$ CI 0.64 to 0.76$)$ for eczema and $0.67(95 \%$ CI 0.52 to 0.86$)$ for hay fever). In contrast, the presence of older siblings increased the incidence of asthma (HR 1.17 , 95\% CI 1.06 to 1.29 ), although this effect was strongly dependent on age of diagnosis. For children diagnosed over the age of 2 years the presence of older siblings was protective (HR $0.66,95 \%$ CI 0.52 to 0.82 ), while below this age the reverse was true (HR 1.38, 95\% CI 1.24 to 1.54). Members of a multiple birth had a reduced incidence of all three allergic diseases. Birth order and multiple birth effects were independent of sex, maternal age, consulting behaviour, and parental allergy and smoking habit.

Conclusions-The presence of older siblings and being a member of a multiple birth appears to protect against the development of eczema, hay fever, and asthma diagnosed after the age of 2 . In contrast, the presence of older siblings increases the incidence of early asthma.

(Thorax 2001;56:758-762)

Keywords: allergy; asthma; eczema; hay fever; birth order; multiple births

In 1989 , in an analysis of the 1958 British birth cohort, Strachan showed that the presence of older siblings appeared to protect against the risk of later developing hay fever and suggested that this effect might be mediated by infection. ${ }^{1}$ A number of other studies have now reported similar findings, providing support for Strachan's hygiene hypothesis that early life infection protects against the development of allergy. To date, the strongest and most consistent data come from studies of hay fever and eczema, ${ }^{2-5}$ while the data for asthma are conflicting. ${ }^{2-11}$ The inconsistent results for asthma may reflect the more complex aetiology of wheezing illness. For instance, wheezing early in life may be provoked by respiratory infections and therefore increased by the presence of older siblings, while wheezing later in life may be driven by allergic sensitisation and thus be decreased by the presence of older siblings. ${ }^{12}$ The impact of birth order on the risk of asthma is therefore likely to depend critically on the age of the children studied. A major limitation of many of the studies undertaken to date is that they are either cross sectional or serial cross sectional analyses of a cohort and, in order to determine more clearly whether there is a crossover of the impact of birth order on asthma and wheezing, more detailed longitudinal data are required. ${ }^{1-11}$

Children who are members of a multiple birth may be likely to have increased exposure to infections early in life from close contact between members so, if the hygiene hypothesis is true, such children should have a decreased incidence of allergic disease. To date, however, the evidence to support this is limited to two studies within twins showing reduced prevalence of allergic rhinitis and asthma, and another showing reduced admissions to hospital for asthma..$^{13} 14$

The aim of this study was to quantify the effects of birth order and multiple births on the incidence of asthma, eczema, and hay fever and to investigate whether these effects remain constant with increasing age. To do this we have performed a birth cohort analysis using the West Midlands General Practice Research Database (GPRD).

\section{Methods}

Our subjects consisted of an historical birth cohort of children identified from the West Midlands section of the GPRD. The GPRD is the largest source of longitudinal primary care data available and participating practices are audited to ensure that their patient records include $95 \%$ of prescribing and morbidity events. The West Midlands section of the GPRD includes 53 participating practices with data for over 650000 people.

In establishing our cohort we tried to include all children with complete follow up data from birth and used the following parameters. We included all children born after each practice who satisfied the collection standards for 
research quality data provided that the child was registered with the GP within 3 months of their recorded date of birth. We chose this cut off point after plotting a histogram of the times between date of birth and registration. This plot showed that most children were registered within 3 months of their date of birth, and during this period the data followed a normal distribution. After 3 months the registration rate was low and constant - that is, more in keeping with children changing GPs and re-registering. In addition, children were only included in the cohort if their medical history contained at least one consultation (excluding consultations for allergic diseases and vaccination) as an indicator that the child was using this GP for their medical needs.

We used a combination of practice code and family code to establish the family structure for each cohort child. The number of older siblings was determined by counting the number of people with the same family code as the subject who were born in the period of 16 years before the subject was born, excluding any mothers who would fit this criteria and families with more then 13 members or less than two members. Younger siblings were defined similarly as the number of people born within a family code after the subject was born. Siblings having the same date of birth were identified as multiple births and categorised as twins, triplets, or quadruplets. For the purpose of this study, women were defined as "mothers" if they lived in the same house as the child and had a birth code recorded within 90 days of the child's date of birth, and "fathers" when there was only one man having the same family code as the child and aged $18-45$ at the birth of the child.

Incident diagnoses of asthma (including codes for asthma and wheezing), eczema, and hay fever were identified using the relevant OXMIS and Read codes (full code lists available from the authors). Data were then extracted for parental diagnoses of asthma, eczema, and hay fever, and smoking habit. Smoking status was coded as non-smoker, ex-smoker, current smoker, or unknown smoking history. To attain an estimate of the frequency of visits to the doctor, we extracted the number of medical visits recorded in 6 month intervals from birth, excluding visits for vaccinations and allergic disease outcomes.

\section{STATISTICAL ANALYSIS}

The impact of birth order on the incidence of each allergic disease was examined by Cox regression with robust standard errors using StATA 5.0, (Stata Corporation, Texas, USA). To look for evidence of confounding by other exposures, each of these was added to the Cox regression model. Where there were missing data for a potential confounder, these were fitted as a separate category to ensure that nested models contained the same number of observations. To test that the proportional hazards assumption held over time for our models we used a combination of the STATA phtest 1 command and Aalen plots. Where the proportional hazard assumption was not met, the hazard ratios were examined either side of the mid point of the total person-years.

\section{Results}

DEMOGRAPHIC DATA AND THE INCIDENCE OF

ASTHMA, ECZEMA, AND HAY FEVER

The cohort contained 29238 children $(51 \%$ boys) with a median follow up time of 2.9 years (range 0-11). Table 1 shows the baseline characteristics of the population. Information on siblings was available for $95 \%$ of the cohort and the main reason for missing data was the failure of one practice to use the family identifier code. We were able to identify confirmed mothers for $84 \%$ of our cohort and the yield for identified fathers was lower at $57 \%$. Some record of smoking habit was identified for $84 \%$ $(n=20733)$ of mothers and, of these, $24 \%$ (5003) were current smokers. For fathers we identified a smoking record for $12087(72 \%)$, $32 \%$ of whom were current smokers. The prevalence of allergic disease for mothers was $38 \%$ and for fathers was $25 \%$.

The incidence of allergic disease was 7.3 per 100 person-years for asthma, 12.4 per 100 person-years for eczema, and 1.2 per 100 person-years for hay fever; the incidence of

Table 1 Baseline characteristics of subjects $(n=29$ 238)

\begin{tabular}{|c|c|c|}
\hline & $n$ & $\%$ \\
\hline \multicolumn{3}{|l|}{ Sex } \\
\hline Male & 14297 & 51.2 \\
\hline Female & 14281 & 48.8 \\
\hline \multicolumn{3}{|l|}{ Mother } \\
\hline Confirmed & 24690 & 84.4 \\
\hline No mother & 4548 & 15.6 \\
\hline \multicolumn{3}{|c|}{ Mother allergic disease } \\
\hline No & 15201 & 61.6 \\
\hline Yes & 9489 & 38.4 \\
\hline \multicolumn{3}{|c|}{ Mother's smoking habits } \\
\hline Non-smoker & 13058 & 52.9 \\
\hline Ex-smoker & 2672 & 10.8 \\
\hline Current smoker & 5003 & 20.3 \\
\hline Unknown & 3957 & 16.0 \\
\hline \multicolumn{3}{|c|}{ Mother's age at birth of child } \\
\hline$<23.9$ & 4987 & 20.2 \\
\hline $24.0-27.3$ & 4953 & 20.0 \\
\hline $27.4-30.1$ & 4927 & 20.0 \\
\hline $30.2-33.2$ & 4873 & 19.8 \\
\hline$>33.2$ & 4950 & 20.0 \\
\hline \multicolumn{3}{|l|}{ Father } \\
\hline Likely father & 16745 & 57.3 \\
\hline No father & 12493 & 42.7 \\
\hline \multicolumn{3}{|c|}{ Father allergic disease } \\
\hline No & 12604 & 75.3 \\
\hline Yes & 4141 & 24.7 \\
\hline \multicolumn{3}{|c|}{ Father's smoking habit } \\
\hline Non-smoker & 6823 & 40.8 \\
\hline Ex-smoker & 1422 & 8.5 \\
\hline Current smoker & 3842 & 22.9 \\
\hline Unknown & 4658 & 27.8 \\
\hline \multicolumn{3}{|l|}{ No of consultations } \\
\hline $0-3$ & 9259 & 31.7 \\
\hline $4-6$ & 10632 & 36.4 \\
\hline $7-8$ & 4414 & 15.1 \\
\hline$>8$ & 4933 & 16.9 \\
\hline \multicolumn{3}{|l|}{ Older siblings } \\
\hline 0 & 11404 & 39.0 \\
\hline 1 & 9502 & 32.5 \\
\hline 2 & 4259 & 14.6 \\
\hline$>2$ & 2494 & 8.5 \\
\hline Unknown & 1579 & 5.4 \\
\hline \multicolumn{3}{|l|}{ Younger siblings } \\
\hline 0 & 21423 & 73.3 \\
\hline 1 & 5268 & 18.0 \\
\hline$>1$ & 968 & 3.3 \\
\hline Unknown & 1579 & 5.4 \\
\hline \multicolumn{3}{|l|}{ Multiple births } \\
\hline None & 26648 & 96.3 \\
\hline Twins & 965 & 3.5 \\
\hline Triplets/quads & 46 & 0.2 \\
\hline
\end{tabular}




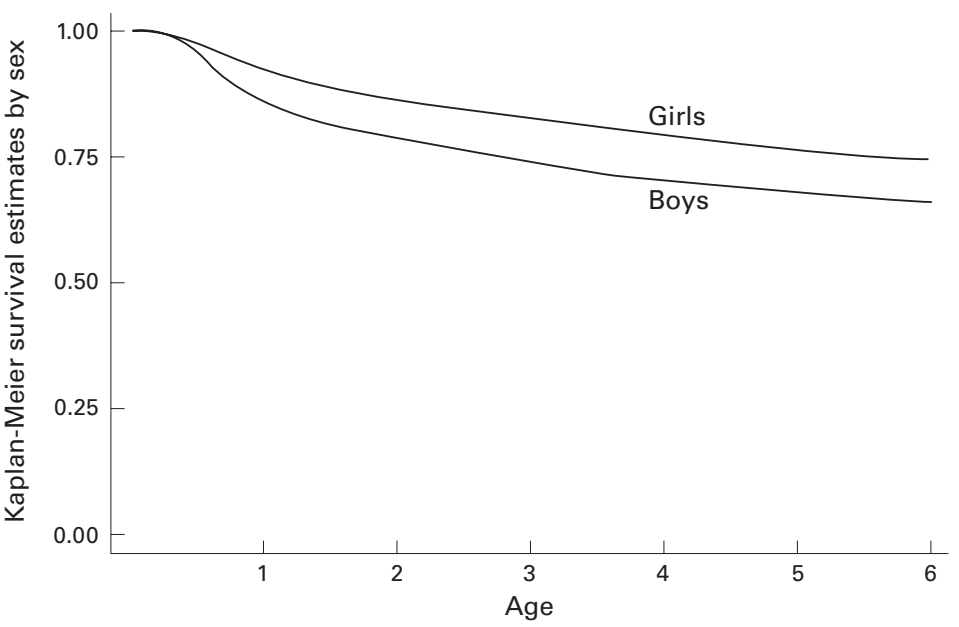

Figure 1 Kaplan-Meier plot for asthma according to sex.

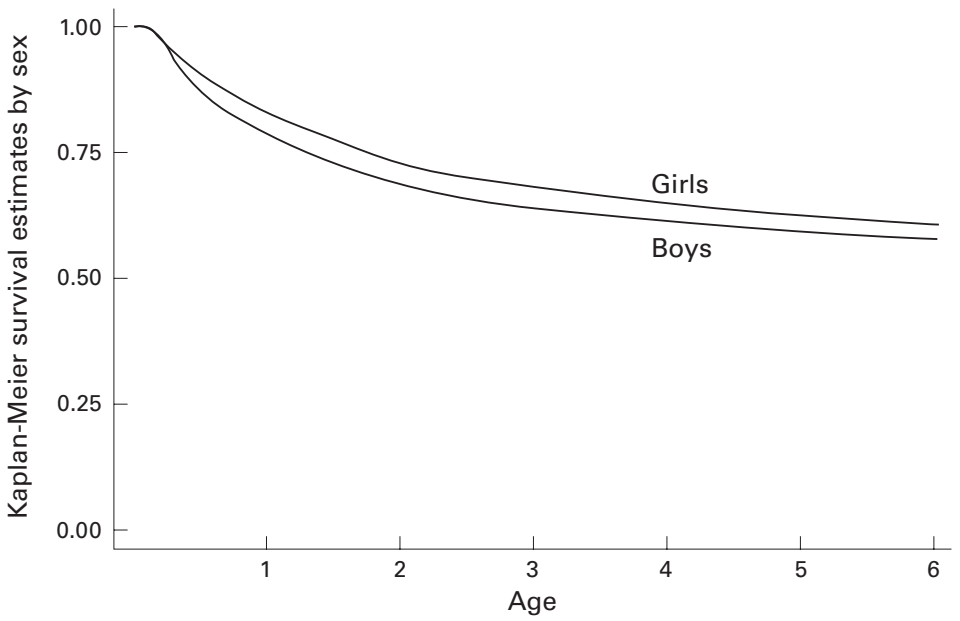

Figure 2 Kaplan-Meier plot of eczema according to sex.

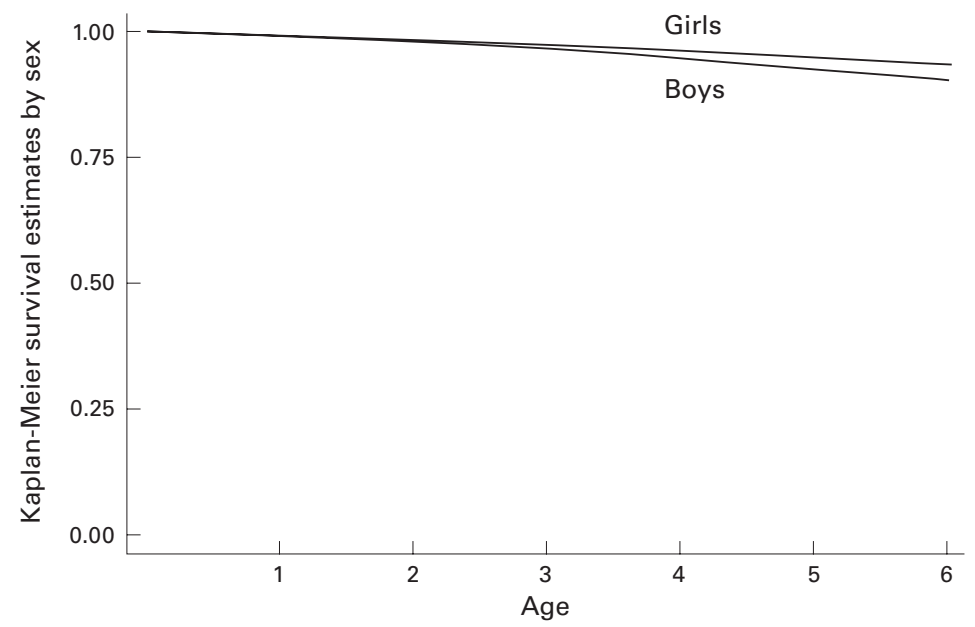

Figure 3 Kaplan-Meier plot for hay fever according to sex.

each allergic disease stratified by sex is shown in figs 1-3. In total, there were 5842 cases of asthma, 8839 cases of eczema, and 1113 cases of hay fever. The median age of diagnosis for asthma was 1 year, for eczema was 9 months, and for hay fever was 2.75 years.

UNIVARIATE EFFECT OF SIBLINGS

The incidence of eczema and hay fever showed a clear inverse association with increasing number of older siblings (table 2), and this effect did not vary over time. There was no consistent pattern between the incidence of eczema or hay fever and the number of younger siblings. In contrast, the risk of asthma was positively associated with the number of older siblings. This effect was age dependent, however, and our model did not meet the proportional hazards assumption (phtest1, $\mathrm{p}=0.007$ ). We therefore divided the data at the median person-years (2.1 years) and found a stronger positive relationship with the number of older siblings in the first half but, for disease diagnosed in the second half, an increased number of older siblings was associated with a decreased incidence of asthma (table 3 ). When we examined the data further in a series of post hoc analyses, the crossover between an increase or decrease in the incidence of asthma with older siblings appeared to occur at 1 year of age (data not shown). A total of 3013 children $(52 \%)$ had a diagnosis of asthma and 2829 (48\%) a diagnosis of just wheeze. Restricting the outcome purely to a diagnosis of asthma rather than to wheeze or asthma gave similar results, although the impact of older siblings on early diagnosis of asthma ( $<2$ years) was marginally attenuated.

Children who are twins, triplets, or quadruplets were less likely to have incident asthma and eczema than singletons, and there was a progressive decrease in the risk of disease with increasing number of children within a multiple birth. No triplets or quadruplets developed hay fever, but twins had a reduced risk of hay fever (HR 0.85 (95\% CI 0.58 to 1.24)). Because of our findings of a crossover age for the impact of older siblings on the incidence of asthma, we performed a similar series of post hoc analyses for the impact of multiple birth. Although numbers were small, there did not appear to be a protective effect of being part of a multiple birth under 1 year, while for asthma there was evidence of a dose-related protective effect after this age.

EFFECT OF POTENTIAL CONFOUNDERS

Boys had a greater risk of developing all three allergic diseases than girls (table 2). Parental allergic disease was associated with an increased risk of asthma, eczema, and hay fever, and these associations were stronger in relation to allergic disease in mothers than fathers. Exposure to maternal passive smoking was associated with an increased risk of asthma, although the effect was dependent on age of diagnosis (phtest $1, p<0.0001$ ) and the effect was confined to the first half of person-year time ( $<2.1$ years, HR 1.34 (95\% CI 1.24 to 1.45 ) in current $v$ non-smokers) and was not present during the second half of person-years time (HR 1.00 (95\% CI 0.84 to 1.17)). The pattern was similar for paternal smoking exposure. Both maternal and paternal smoking tended to be associated with a small decrease in the incidence of the other allergic diseases (table 2).

Children born to older mothers had a decreased incidence of asthma such that, for the oldest quintile of mothers (aged over 33) 
Table 2 Hazard ratios for univariate analysis

\begin{tabular}{|c|c|c|c|c|c|c|}
\hline & \multicolumn{2}{|c|}{ Asthma } & \multicolumn{2}{|c|}{ Eczema } & \multicolumn{2}{|c|}{ Hay fever } \\
\hline & $H R$ & $95 \% C I$ & $H R$ & $95 \% C I$ & $H R$ & $95 \% C I$ \\
\hline \multicolumn{7}{|l|}{ Sex } \\
\hline Boys & 1.00 & & 1.00 & & 1.00 & \\
\hline Girls & 0.65 & 0.61 to 0.68 & 0.86 & 0.82 to 0.90 & 0.77 & 0.68 to 0.87 \\
\hline \multicolumn{7}{|c|}{ Mother allergic disease } \\
\hline No & 1.00 & & & & 1.00 & \\
\hline Yes & 1.52 & 1.44 to 1.61 & 1.31 & 1.26 to 1.37 & 1.89 & 1.66 to 2.14 \\
\hline \multicolumn{7}{|l|}{$\begin{array}{l}\text { Mother's smoking } \\
\text { habit }\end{array}$} \\
\hline Non-smoker & 1.00 & & 1.00 & & 1.00 & \\
\hline Ex-smoker & 1.22 & 1.12 to 1.33 & 0.95 & 0.88 to 1.02 & 1.09 & 0.89 to 1.33 \\
\hline Current smoker & 1.36 & 1.27 to 1.45 & 0.85 & 0.80 to 0.90 & 0.88 & 0.75 to 1.05 \\
\hline Unknown & 1.11 & 1.02 to 1.20 & 0.89 & 0.84 to 0.96 & 1.03 & 0.86 to 1.23 \\
\hline \multicolumn{7}{|c|}{ Mother's age at birth of child } \\
\hline$<23.9$ & 1.00 & & 1.00 & & 1.00 & \\
\hline $24.0-27.3$ & 0.95 & 0.88 to 1.04 & 1.04 & 0.97 to 1.11 & 1.11 & 0.91 to 1.34 \\
\hline $27.4-30.1$ & 0.91 & 0.83 to 0.99 & 1.14 & 1.06 to 1.22 & 1.03 & 0.85 to 1.26 \\
\hline $30.2-33.2$ & 0.88 & 0.81 to 0.96 & 1.05 & 0.98 to 1.13 & 1.05 & 0.86 to 1.27 \\
\hline$>33.2$ & 0.77 & 0.71 to 0.85 & 0.96 & 0.89 to 1.03 & 0.84 & 0.68 to 1.04 \\
\hline \multicolumn{7}{|c|}{ Father allergic disease } \\
\hline No & 1.00 & & 1.00 & & 1.00 & \\
\hline Yes & 1.29 & 1.20 to 1.39 & 1.27 & 1.20 to 1.35 & 1.14 & 0.97 to 1.35 \\
\hline \multicolumn{7}{|c|}{ Father's smoking habit } \\
\hline Non-smoker & 1.00 & & 1.00 & & 1.00 & \\
\hline Ex-smoker & 1.12 & 0.99 to 1.26 & 0.95 & 0.86 to 1.05 & 1.40 & 1.10 to 1.79 \\
\hline Current smoker & 1.34 & 1.24 to 1.46 & 0.91 & 0.85 to 0.98 & 0.97 & 0.79 to 1.19 \\
\hline Unknown & 0.97 & 0.89 to 1.06 & 0.87 & 0.81 to 0.93 & 1.00 & 0.83 to 1.21 \\
\hline \multicolumn{7}{|l|}{ No of consultations } \\
\hline $0-3$ & 1.00 & & 1.00 & & 1.00 & \\
\hline $4-6$ & 1.60 & 1.49 to 1.72 & 1.32 & 1.25 to 1.40 & 1.70 & 1.43 to 2.01 \\
\hline $7-8$ & 2.09 & 1.92 to 2.27 & 1.61 & 1.51 to 1.72 & 2.31 & 1.91 to 2.80 \\
\hline$>8$ & 3.02 & 2.80 to 3.26 & 1.86 & 1.75 to 1.98 & 2.79 & 2.33 to 3.34 \\
\hline \multicolumn{7}{|l|}{ No of older siblings } \\
\hline 0 & 1.00 & & 1.00 & & 1.00 & \\
\hline 1 & 1.13 & 1.06 to 1.20 & 0.89 & 0.85 to 0.94 & 0.82 & 0.72 to 0.94 \\
\hline 2 & 1.18 & 1.09 to 1.27 & 0.82 & 0.76 to 0.87 & 0.76 & 0.63 to 0.91 \\
\hline$>2$ & 1.17 & 1.06 to 1.29 & 0.70 & 0.64 to 0.76 & 0.67 & 0.52 to 0.86 \\
\hline \multicolumn{7}{|c|}{ No of younger siblings } \\
\hline 0 & 1.00 & & 1.00 & & 1.00 & \\
\hline 1 & 0.98 & 0.92 to 1.04 & 1.08 & 1.03 to 1.14 & 0.99 & 0.86 to 1.13 \\
\hline$>1$ & 0.94 & 0.83 to 1.07 & 0.94 & 0.85 to 1.05 & 1.11 & 0.88 to 1.41 \\
\hline \multicolumn{7}{|c|}{ No of multiple births } \\
\hline None & 1.00 & & 1.00 & & 1.00 & \\
\hline Twins & 0.83 & 0.70 to 0.97 & 0.74 & 0.65 to 0.85 & 0.85 & 0.58 to 1.24 \\
\hline Triplets/quads & 0.59 & 0.27 to 1.30 & 0.43 & 0.20 to 0.89 & $\star$ & \\
\hline
\end{tabular}

^Insufficient numbers to be completed.

compared with the youngest quintile (under 24), the HR for asthma was 0.77 (95\% CI 0.66 to 0.78 ). This relationship was time dependent (phtest $1, \mathrm{p}<0.0001$ ) and was stronger in the first half than in the second half of person-year time. There was no relationship between age of the mother and development of eczema or hay fever.

Subjects who were more frequent visitors to their GP for conditions unrelated to allergies had an increased incidence of allergic disease. Visiting the GP $>8$ times in the first 6 months was associated with an HR for asthma of 3.02 (95\% CI 2.80 to 3.26 ), for eczema of 1.86 (95\% CI 1.75 to 1.98$)$, and for hay fever of 2.79 (95\% CI 2.33 to 3.34) compared with 0-3 consultations. Using other time intervals of consulting produced similar results.

Table 3 Number of older siblings and incidence of asthma in the two different periods of person-year time

\begin{tabular}{|c|c|c|c|c|c|c|}
\hline \multirow[t]{2}{*}{$\begin{array}{l}\text { No of older } \\
\text { siblings }\end{array}$} & \multicolumn{2}{|c|}{ Asthma at any time } & \multicolumn{2}{|c|}{$\begin{array}{l}\text { Asthma diagnosed } \\
\text { at }<2.1 \text { years }\end{array}$} & \multicolumn{2}{|c|}{$\begin{array}{l}\text { Asthma diagnosed at } \\
>2.1 \text { years }\end{array}$} \\
\hline & $H R$ & $95 \% C I$ & $H R$ & $95 \% C I$ & $H R$ & $95 \% C I$ \\
\hline 0 & 1.00 & & 1.00 & & 1.00 & \\
\hline 1 & 1.13 & 1.06 to 1.20 & 1.30 & 1.21 to 1.40 & 0.90 & 0.80 to 1.01 \\
\hline 2 & 1.18 & 1.09 to 1.27 & 1.42 & 1.30 to 1.55 & 0.78 & 0.67 to 0.92 \\
\hline$>3$ & 1.17 & 1.06 to 1.28 & 1.38 & 1.24 to 1.54 & 0.66 & 0.52 to 0.82 \\
\hline
\end{tabular}

MULTIVARIATE ANALYSIS

Multivariate analyses were conducted to assess the potential confounding effects of sex, age, maternal and/or paternal allergic disease, maternal and/or paternal smoking, and consulting behaviour on the birth order/multiple birth effect. However, all of the adjusted hazard ratios for older siblings, multiple birth, and other potential confounders were within $10 \%$ of the initial univariate values and most were within $1 \%$. In addition, adjusting for specific general practice did not affect the results.

\section{Discussion}

In this study we have used longitudinal data collected as part of usual primary care and have demonstrated a dose related protective effect of older siblings on the incidence of eczema and hay fever. A similar birth order effect was present for asthma where the age of onset is $>2$ years and possibly over the age of 1 year, but before this the opposite is true. The protective effect of exposures to siblings in early life is also reflected in a decreased risk of developing all three allergic diseases in children who are members of multiple births, again in a dose related manner. These birth order and multiple birth effects did not appear to be explained by consulting behaviour, parental smoking or allergic disease, or age of the mother at birth.

There are limitations to using routine general practice data for research. Since we relied on the medical record for the diagnoses of asthma, eczema, and hay fever, there is potential for misclassification of disease status. It is likely, however, that any misclassification will be random with respect to birth order so, even if present, this will tend to bias our results towards unity. Many studies rely on parental reporting of child symptoms or diagnoses; this study relies on parents reporting symptoms to the GP so there is potential for ascertainment bias. We were able to attempt to assess the likely impact of consulting behaviour by adjusting our analyses for general consulting behaviour at various time intervals and found that, although consulting behaviour was strongly associated with disease diagnosis, it had little or no impact upon the birth order effects. Another potential source of misclassification arises from record linking family members. While we have used all means available to us to confirm the identification of mothers, fathers and siblings, it is probable that some error is present; again, this is unlikely to be systematic with respect to birth order and so would have generally tended to bias our results towards unity. Parental smoking status may also contain some misclassification since general practitioners do not ask about smoking at every consultation and so some smoking data will be out of date or missing. We have previously shown that, within the GPRD, among the elderly most ex-smokers are coded as non-smokers but that data for current smokers appear to be accurate,${ }^{15}$ and when assessing the impact of environmental tobacco smoke on wheeze the most important distinction is between current and non-current smoking. A further limitation of the GPRD is that it 
contains no marker of social class at the individual level and this means we cannot adjust for this important confounder. However, we did adjust for two variables which may be considered proxy markers of social classsmoking habit and age of mother at first birth (data not shown) - and neither had any impact on the birth order or multiple birth effects.

Despite these limitations, the GPRD provides many benefits. We were able to establish a large representative cohort of children and the longitudinal nature of the data allowed us to examine the effect of exposures on incidence rather than prevalence of disease and to examine how the effect of the exposure varied with time. We also had sufficient statistical power to look at relatively rare exposures such as being part of a multiple birth. Our findings of an increased risk of allergic disease with a family history of allergic disease and an increased risk of early asthma with parental smoking and younger maternal age are consistent with other studies. ${ }^{7811}$

The relationships between the number of older siblings and decreased risk of eczema and hay fever have been reported previously, ${ }^{2-5}$ although the size of the present cohort means that our estimates are perhaps the most precise to date. The results of previous research have been less consistent about the relationship between number of older siblings and development of asthma. ${ }^{2-11}$ Our data clearly show that the impact of older siblings is dependent upon the age at which the disease develops. For asthma diagnosed after 2 years of age, the presence of older siblings provides the same protective effect as for the other allergic diseases, and our post hoc analyses suggest that this protective effect may emerge at 1 year. In contrast, the presence of older siblings increases the risk of asthma diagnosed earlier than this. The most likely explanation for these findings is that the presence of older siblings increases the incidence of early respiratory tract infections and a diagnosis of wheeze resulting from these infections is recorded. Evidence to support this crossover effect of older siblings comes from a study showing that children with one or more older siblings or attending day care were more likely to have early wheezing but were protected from later onset of asthma, ${ }^{15}$ and from the finding that siblings increase the risk of transient early wheezing but protect against late onset wheezing. ${ }^{11}$

The evidence regarding the risk of allergy among members of a multiple birth is limited, primarily because the datasets required to investigate such questions need to be very large. One study has reported a lower prevalence of both asthma and allergic rhinitis among twins ${ }^{13}$ and another study has shown that twins have an increased risk of hospital admission with bronchitis/bronchiolitis but a decreased risk of admission for asthma. ${ }^{14}$ Our results clearly show an inverse dose-response relationship between increasing number of members of a multiple birth and risk of allergic disease. Although statistical power was limited for our post hoc analyses, the protective effect for asthma did not appear to be present under the age of 1 year.

Previous research has suggested that wheezing and asthma are more common in boys than in girls, ${ }^{16}$ and it has been suggested that this is a physiological phenomenon resulting from their smaller airways. ${ }^{17}$ Our findings, however, suggest that boys are also at an increased risk for eczema and hay fever, although the size of these effects was smaller than that for asthma. This suggests that the reason why boys have more asthma than girls is partly due to an increased incidence of allergy in boys. More research needs to be conducted in order to clarify why boys at this age are at an increased risk of allergic disease.

In summary, children who have older siblings or who are born as part of a multiple birth are less likely to develop eczema or hay fever, and asthma after the age of 2 years, but are more likely to have asthma diagnosed in the first year of life.

This study was funded by the National Asthma Campaign.

1 Strachan DP. Hay fever, hygiene, and household size. $B M \mathcal{F}$ 1989;299:1259-60

2 Wickens K, Crane J, Pearce N, et al. The magnitude of the effect of smaller family sizes on the increase in the prevalence of asthma and hay fever in the United Kingdom and New Zealand. F Allergy Clin Immunol 1999;104:554-8.

3 Pekkanen J, Remes S, Kajosaari M, et al. Infections in early childhood and risk of atopic disease. Acta Paediatr 1999;88: $710-4$.

4 Ponsonby AL, Couper D, Dwyer T, et al. Cross sectional study of the relation between sibling number and asthma, hay fever, and eczema. Arch Dis Child 1998;79:328-33.

5 Bodner C, Godden D, Seaton A. Family size, childhood infections and atopic diseases. Thorax 1998;53:28-32.

6 Wickens KL, Crane J, Kemp TJ, et al. Family size, infections, and asthma prevalence in New Zealand infections, and asthma prevalence
children. Epidemiology 1999;10:699-705.

7 Lewis S, Richards D, Bynner J, et al. Prospective study of risk factors for early and persistent wheezing in childhood. Eur Respir ₹ 1995;8:349-56.

8 Lewis S, Butland B, Strachan D, et al. Study of the aetiology of wheezing illness at age 16 in two national British birth cohorts. Thorax 1996;51:670-6

9 Rona RJ, Hughes JM, Chinn S. Association between asthma and family size between 1977 and 1994. I Epidemiol Community Health 1999;53:15-9.

10 Rona RJ, Duran Tauleria E, Chinn S. Family size, atopic disorders in parents, asthma in children, and ethnicity. $f$ Allergy Clin Immunol 1997;99:454-60.

11 Rusconi F, Galassi C, Corbo GM, et al. Risk factors for early, persistent, and late-onset wheezing in young
children. SIDRIA Collaborative Group. Am $\mathcal{F}$ Respir Crit Care Med 1999;160:1617-22.

12 Martinez FD, Wright AL, Taussig LM, et al. Asthma and wheezing in the first six years of life. The Group Health Medical Associates. N Engl F Med 1995;332:133-8.

13 Braback L, Hedberg A. Perinatal risk factors for atopic disBraback L, Hedberg A. Perinatal risk factors for atop
ease in conscripts. Clin Exp Allergy 1998;28:936-42.

14 Strachan DP, Moran SE, McInneny K, et al. Reduced risk of hospital admission for childhood asthma among Scottish twins: record linkage study. $B M \mp$ 2000;321:732-3.

15 Ball TM, Castro-Rodriguez JA, Griffith KA, et al. Siblings, day-care attendance, and the risk of asthma and wheezing during childhood. N Engl f Med 2000;343:538-43.

16 Luyt DK, Burton P, Brooke AM, et al. Wheeze in preschool children and its relation with doctor diagnosed asthma. Arch Dis Child 1994;71:24-30.

17 Becklake MR, Kauffmann F. Gender differences in airway behaviour over the human life span. Thorax 1999;54:1119- 